\title{
GROWTH ANALYSIS IN RELATION TO SOWING DATES IN FOUR VARIETIES OF WHEAT: A FUNCTIONAL APPROACH
}

\author{
S. A. Haider* \\ Crop Physiology Laboratory, Department of Botany \\ University of Rajshahi, Rajshahi 6205, Bangladesh
}

\begin{abstract}
Effect of three different sowing dates on growth of four varieties of wheat was analyzed using functional techniques. Crop growth rate (CGR), relative leaf growth rate (RLGR) and specific leaf area (SLA) were higher in the early sown plants compared to late sown plants. Net assimilation rate (NAR) in all the varieties increased slowly at the early stages of growth while it increased sharply at the later stages with fluctuations in most cases. The declining tendency was found in SLA at the middle stage of growth except variety C 306. Higher values of CGR were found in the early sown Protiva, leaf weight ratio (LWR) in the late sown C 306 and early sown Opata, RLGR in the early sown Opata and C 306, SLA in the late sown Opata and Protiva and NAR in all the four varieties when they were sown late.
\end{abstract}

Key words: Wheat, sowing date, growth, functional technique

mui rsk: gW chra Młgi elaxi Dci vew bang

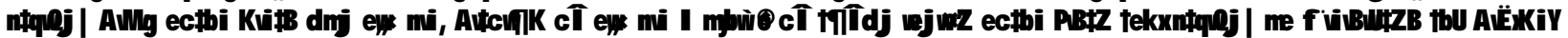

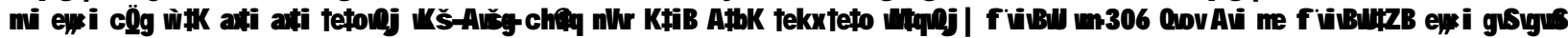
ch myow

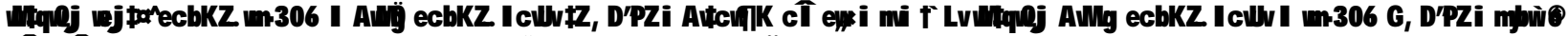

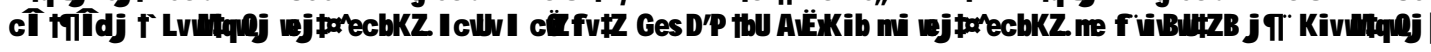

\section{Introduction}

Sowing of wheat in Bangladesh generally starts from November and ends in late December depending on the weather, topography and harvesting of the preceding crops. Late sown wheat seedlings face low temperature in the earlier part and high temperature stress in the later part of the growing season and require favourable moisture for better growth and development in late March and early April. Therefore, sowing date influences the growth, development and yield of wheat.

Analysis of quantitative aspects of growth of whole plant can be effectively conducted using the functional growth analysis techniques which use regression procedure. The polynomial exponential model has a great potential in a purely empirical approach to the study of plant growth, where the objective is to assess and compare either genetic or environmental influences. Grain yield is reported to be positively correlated with growth attributes like CGR, NAR, LAR, RLGR, SLA, LWR (Islam, 1992) but enough information on the aspect of wheat sowing on different dates is not available in Bangladesh. In the present work, effect of sowing dates on the activities of different physiological growth parameters was analyzed using functional technique.

*Email: haider_rubd@yahoo.com

\section{Materials and Methods}

The experiment was carried out in the Botanical Research Field of Rajshahi University, Bangladesh with four wheat (Triticum aestivum L.) varieties, namely, Akbar, Opata, Protiva and C 306. The soil of the experimental field was silty loam having a $\mathrm{pH}$ of 7.5 , low in organic carbon (0.44\%), total $\mathrm{N}(0.43 \%)$, available P (15 ppm) and K (82 $\mathrm{ppm})$. The field capacity of the soil was $34 \%$. A basal dose of urea (80 kg ha $\left.{ }^{-1}\right)$, TSP $\left(60 \mathrm{~kg} \mathrm{ha}^{-1}\right)$ and MP $\left(30 \mathrm{~kg} \mathrm{ha}^{-1}\right)$ were added to the soil during field preparation and before seeding. The experimental design was a split-split plot with three sowing dates (treatments). Three main plots which were considered as treatment (sowing date) plots. Each main plot was subdivided into three replication plots each of $5 \times 3.4 \mathrm{~m}^{2}$ containing all the four varieties assorted randomly. Seeds were sown on $15^{\text {th }}$ November $\left(\mathrm{S}_{1}\right), 15^{\text {th }}$ December $\left(\mathrm{S}_{2}\right)$ and $31^{\text {st }}$ December $\left(\mathrm{S}_{3}\right)$. A $10 \mathrm{~mm}$ irrigation was applied immediately after the seeding on each sowing date and a $20 \mathrm{~mm}$ was applied at the booting stage. There were 6-8 harvests with an equal interval of 10 days. Three plants/variety/replication were harvested on each occasion. The first harvest was made at 19 days after sowing. For dry weights, plant parts were dried at $85^{\circ} \mathrm{C}$ for $24 \mathrm{~h}$ when they reached a constant weight. Leaf area was measured by the disc method (Islam and Paul, 1986). Polynomial functions were fitted to natural logarithmic values of total dry weight, leaf dry weight and total leaf area in the curve fitting method (Hunt, 1979). The $\log _{\mathrm{e}}$ transformation was made in order to render the variance homogeneous with 
time (Hughes and Freeman, 1967). The selection of appropriate polynomial regression model was made by 'lack of fit' method of Nicholls and Calder (1973). The experiment was conducted during 1998-1999 and 1999-2000 growing seasons.

\section{Results and Discussion}

The highest CGR was in plants grown under $S_{1}$, intermediate under $S_{2}$ and the lowest under $S_{3}$ condition at most of the stages of growth in both the growing seasons (Figs 1a \& 1b). This is in agreement with Clarke and Simpson (1978), Sarker and Paul (1998) and Nahar and Paul (1998). Higher CGR in the early sown plants was due to higher production of dry matter owing to higher leaf area index (LAI) (Watson, 1947). As CGR represents the net result of photosynthesis, respiration and canopy area interaction, it is considered as the most meaningful growth function. CGR calculated from the quadratic fitted values increased steadily in all cases up to a certain peak and decreased thereafter. This finding corroborates with that of others (Islam and Soth, 1987).

NAR in all the varieties increased slowly at the early days, but sharply at the later stages of growth in most cases (Figs 2a \& 2b). Similar results were noticed by Buttery (1969), Koller et al. (1970) and Allen and Morgan (1975). Possibly decreased leaf area and increased ear photosynthesis resulted in the increase of NAR at the later stages of growth. The highest NAR values for most of the varieties were found in the late sown condition except Protiva in the first year and Akbar in the second year. NAR of all the varieties showed decreasing tendency towards the last one or two stages of growth. This finding corroborates the results obtained by Haloi and Baldev (1986), due to the mutual leaf shading and increase in the number of older leaves that lost photosynthesis activity (Pandey et al., 1978).

LAR increased in few cases at early stage but in all cases declined steadily with increasing plant age (Figs 3a \& 3b). Wallace and Munger (1965) observed that LAR was highest during the early vegetative stage but later decreased rapidly with the advancement of plant age, possibly due to abscission of older leaves. Similar results were reported by Thorne (1960), Pandey et al. (1978), Haque (1993) and Rahman (1993). Early sown varieties Protiva and C 306 had higher LAR than the other varieties.
RLGR values were decreased with plant age (Figs 4a \& 4b) and such growth trend was reported by many workers (Buttery, 1969; Paul, 1980;. Chanda et al., 1987 and Rahman, 1993). Pandey et al. (1978) opined that abscission of older leaves resulted in the decline of RLGR at the later stages of growth. RLGR was relatively higher in the early sown plants than that of late sown plants in most cases in both the growing seasons.

In all the sowing dates, Akbar, Opata and Protiva had generally higher SLA at the early and later stages of growth but it was lower at the middle stages (Figs 5a \& 5b). The increase of SLA at the later stages might be due to the translocation of assimilates from the leaves to the sink organs. In addition, low demand of photosynthates during the middle stages of growth possibly resulted in lower SLA at the middle stages. C 306 showed decreasing tendency throughout the growing periods in both the growing seasons. These results are in agreement with Chanda et al. (1987). In the present investigation, $\mathrm{S}_{1}$ plants of Opata in the first year and $S_{3}$ plants of Protiva in the next year showed comparatively higher SLA throughout the growing periods. Lower values of SLA were found in the late sown plants of almost all the four varieties.

The curve-fitted values of LWR showed initial increase in some cases, later had downward drifts with increasing plant age in all the varieties and sowing dates (Figs 6a \& 6b). Chanda et al. (1987) also noticed similar growth trends. Increased plant dry weight and decreased LAI at the later stages resulted in the lower LWR at the later stages. Saha and Paul (1995) observed sharp increase of total dry matter resulted in sharp decrease in LWR. Sharp decrease of LWR at the later stages in wheat was also noticed by Sarker and Paul (1998) and Nahar and Paul (1998).

\section{Conclusion}

The results of the present experiment indicate that curve-fitting may be useful for comparative purposes because it can remove fluctuations in data due to sampling error. However, Buttery (1969) opined that curve-fitting can conceal genuine environmental or treatment effects. In most cases, differences between the sowing dates and varieties were observed in the present investigation. Among the growth attributes, CGR, RLGR and SLA increased significantly when they were sown early, NAR decreased more in the early sown plants than the late sown plants at the later stages of growth in most cases. LAR and LWR declined throughout with time and plant weight. 

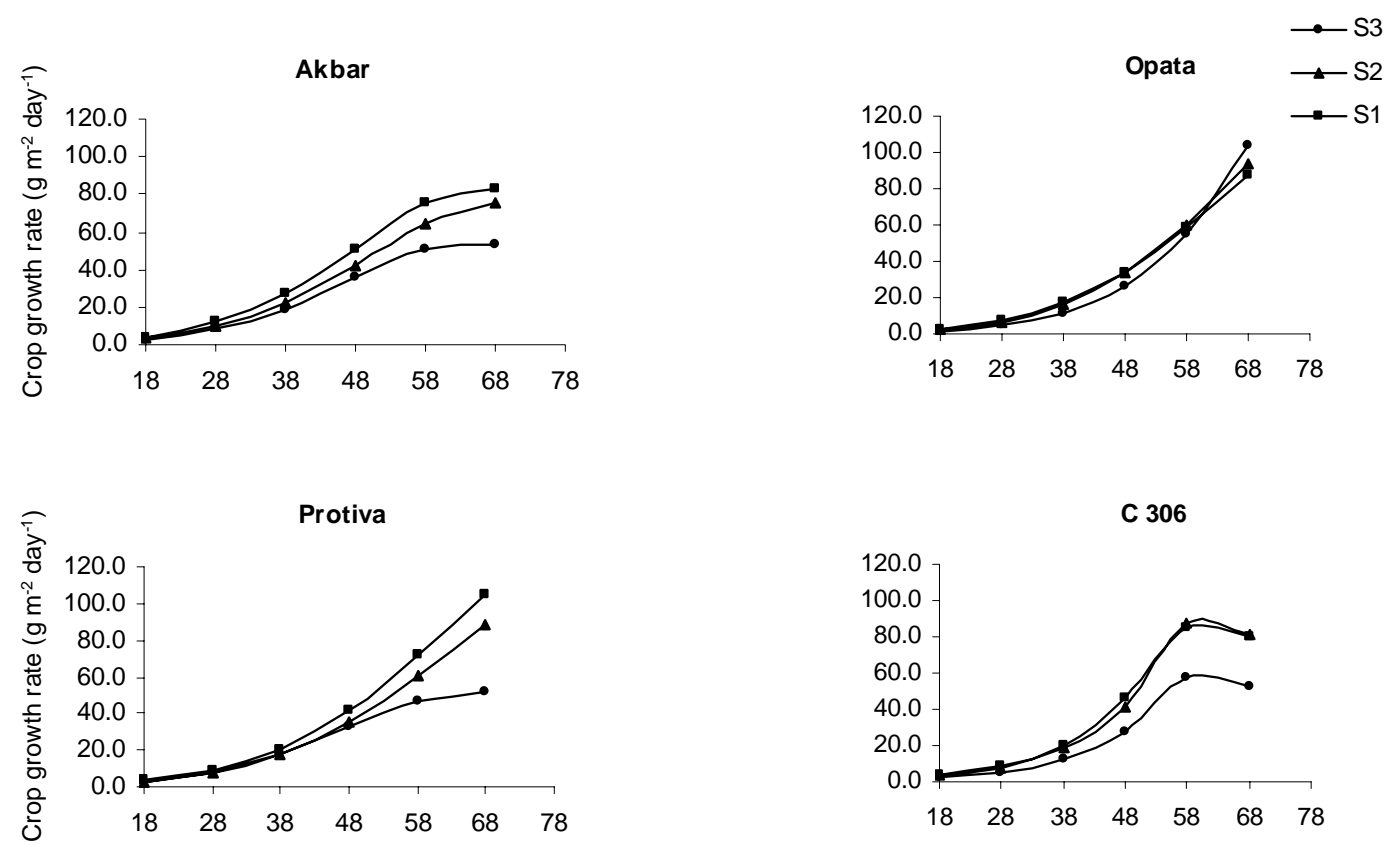

\section{Days after sowing}

Fig. 1a. Effects of different sowing dates on crop growth rate (CGR) of four wheat varieties at different stages of growth from quadratic fitted curve values (First year).
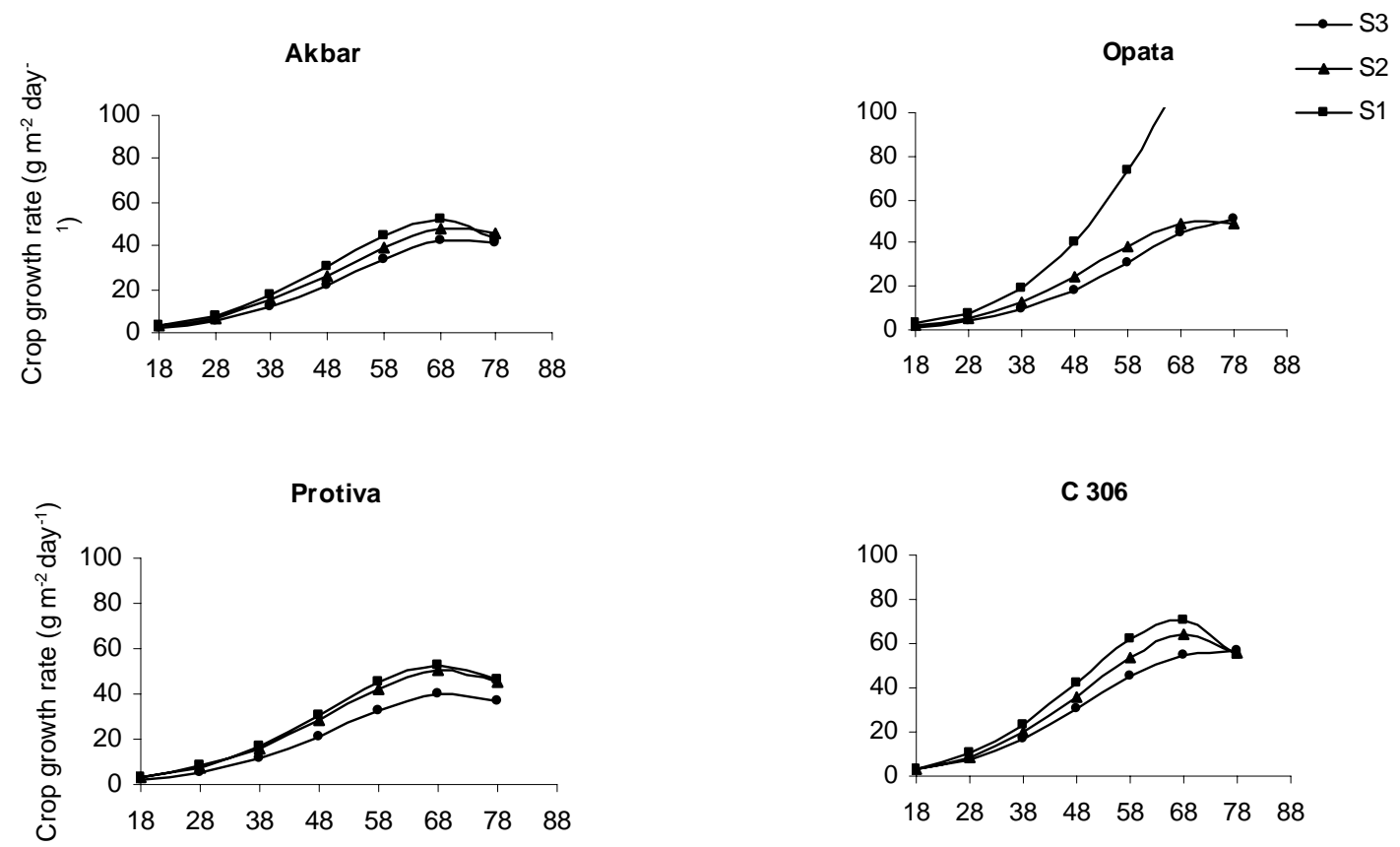

\section{Days after sowing}

Fig. 1b. Effects of different sowing dates on crop growth rate (CGR) of four wheat varieties at different stages of growth from quadratic fitted curve values (Second year). 


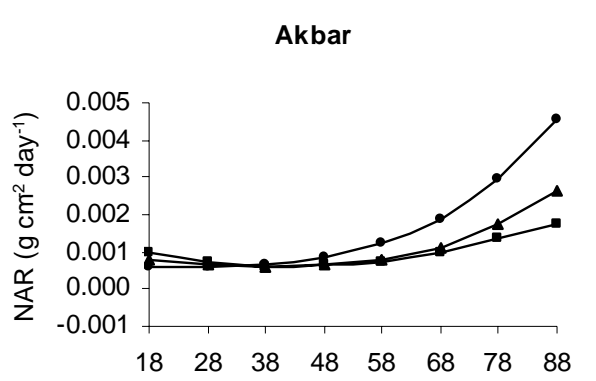

Protiva

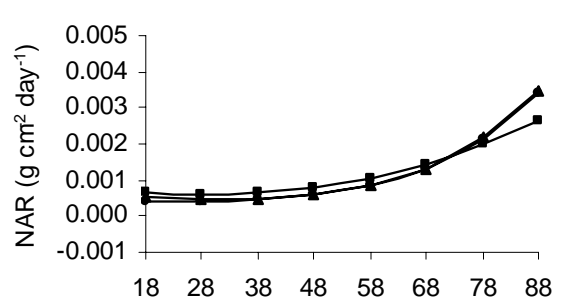

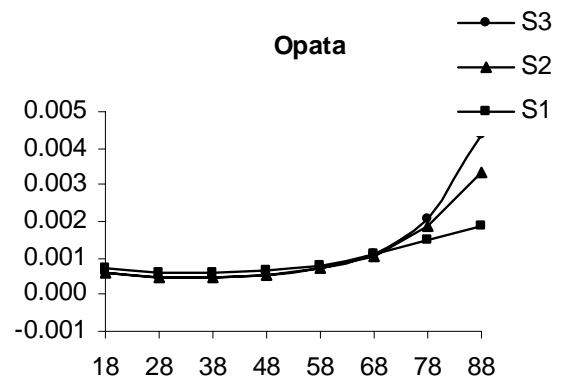

C 306

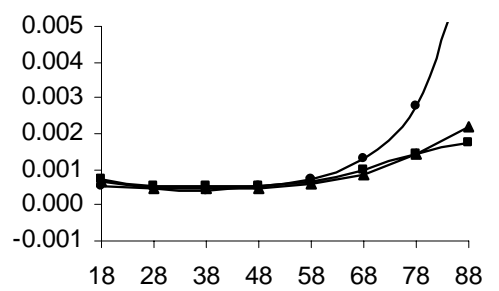

Days after sowing

Fig. 2a. Effects of different sowing dates on net assimilation rate (NAR) of four wheat varieties at different stages of growth from quadratic fitted curve values (First year).
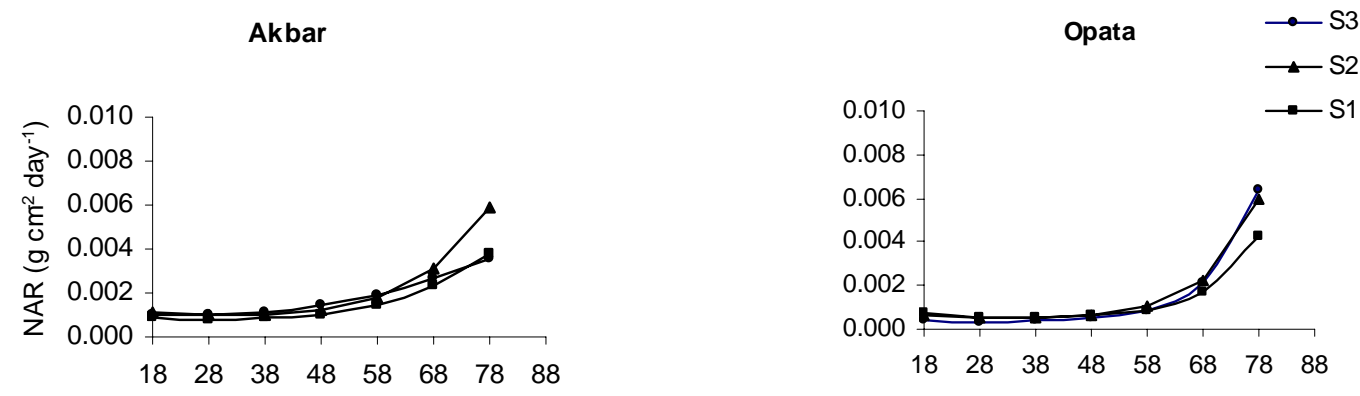

Protiva

C 306
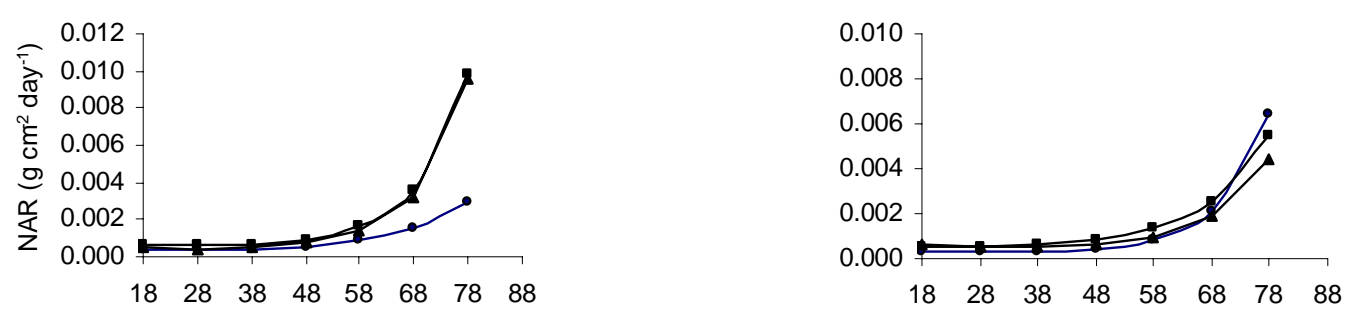

\section{Days after sowing}

Fig. 2b. Effects of different sowing dates on net assimilation rate (NAR) of four wheat varieties at different stages of growth from quadratic fitted curve values (Second year). 

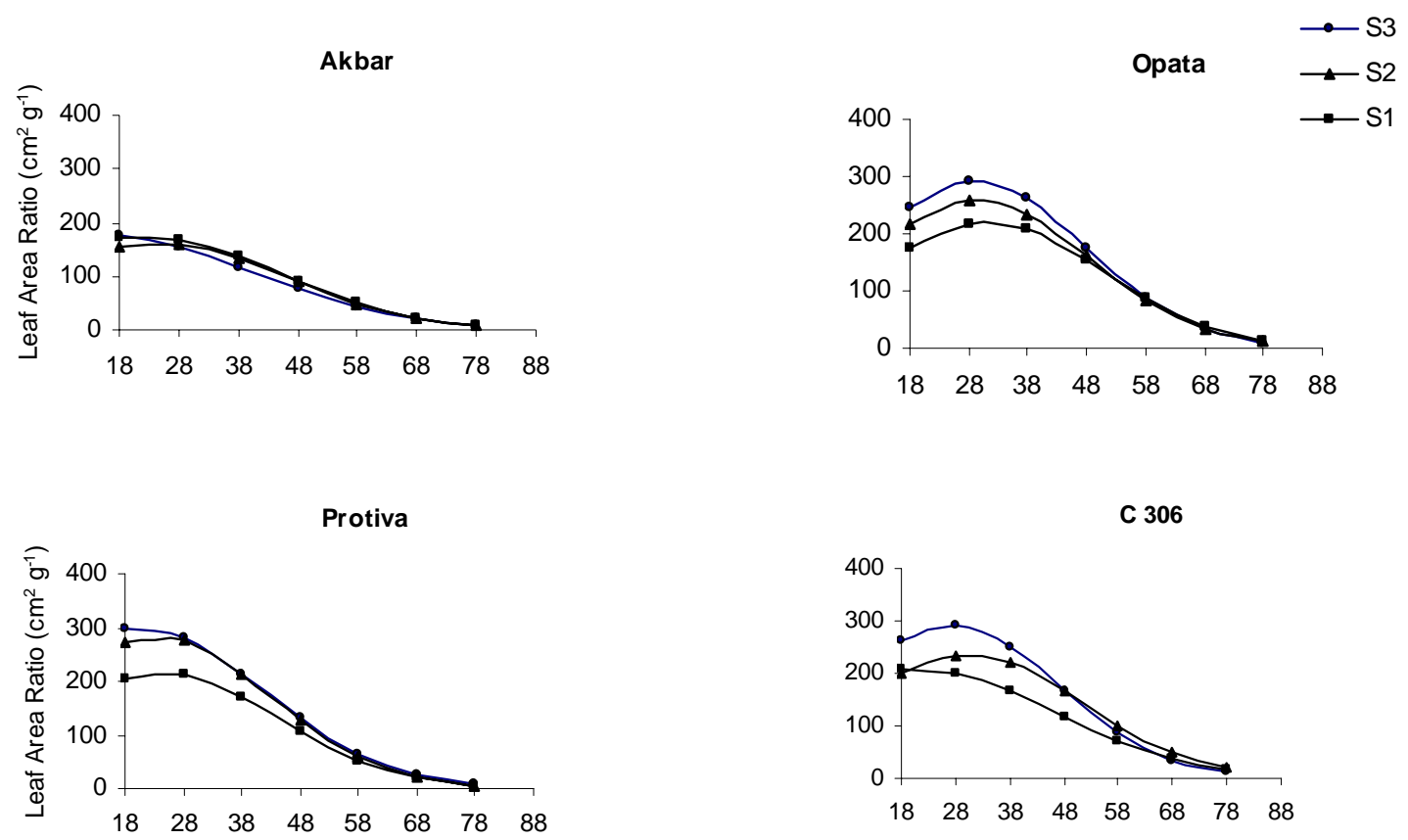

\section{Days after sowing}

Fig. 3a. Effects of different sowing dates on leaf area ratio (LAR) of four wheat varieties at different stages of growth from quadratic fitted curve values (First year).
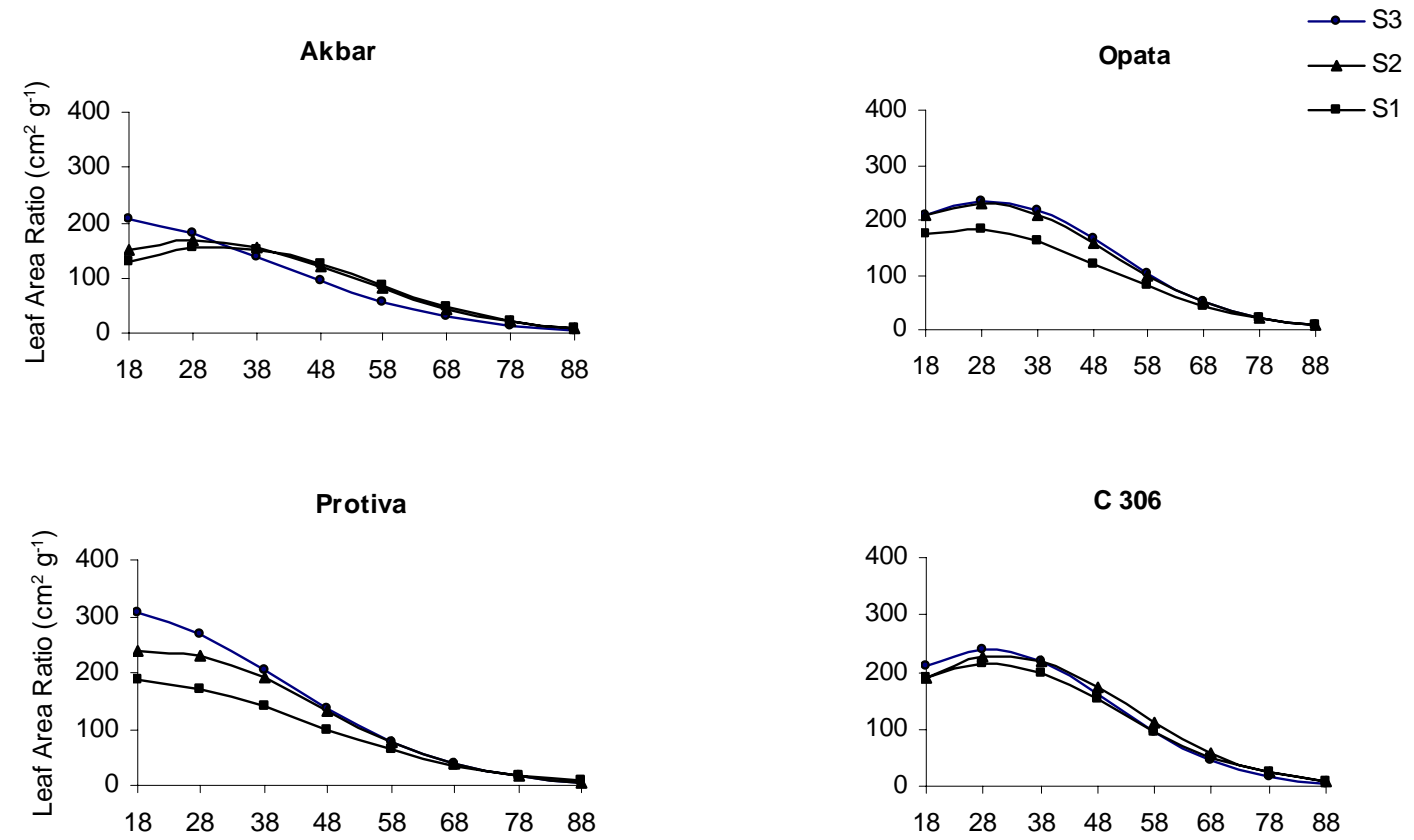

\section{Days after sowing}

Fig. 3b. Effects of different sowing dates on leaf area ratio (LAR) of four wheat varieties at different stages of growth from quadratic fitted curve values (Second year). 

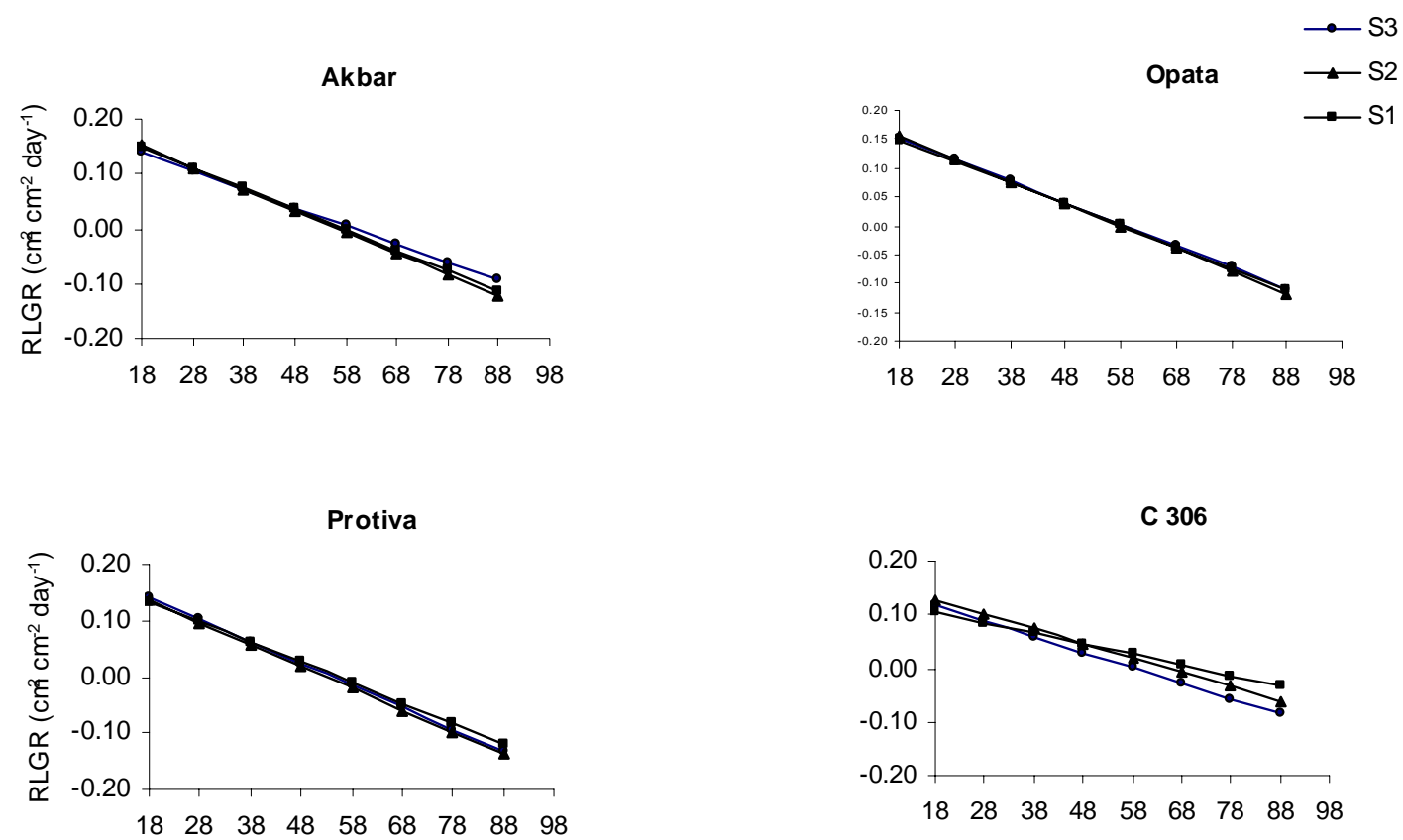

\section{Days after sowing}

Fig. 4a. Effects of different sowing dates on relative leaf growth rate (RLGR) of four wheat varieties at different stages of growth from quadratic fitted curve values (First year).
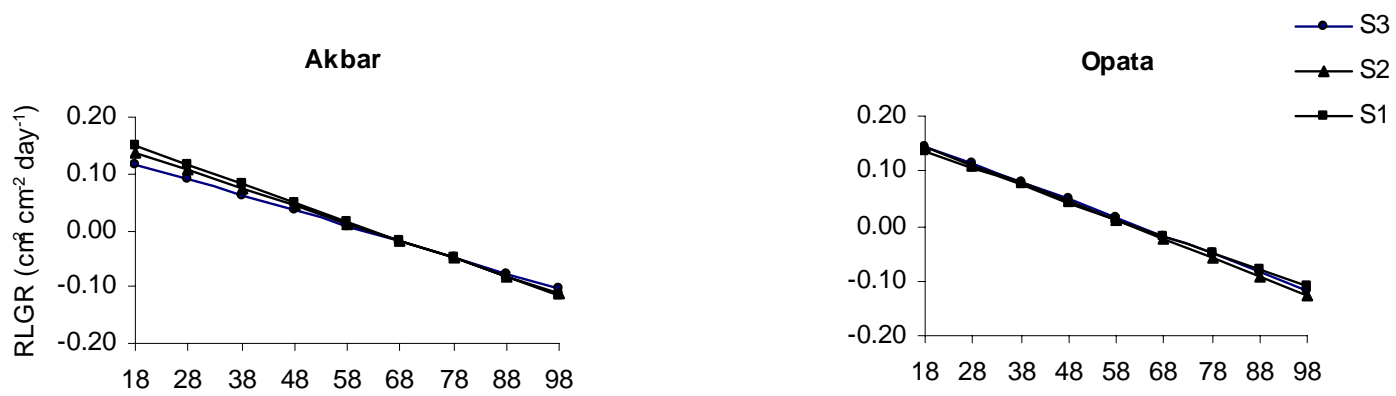

Protiva
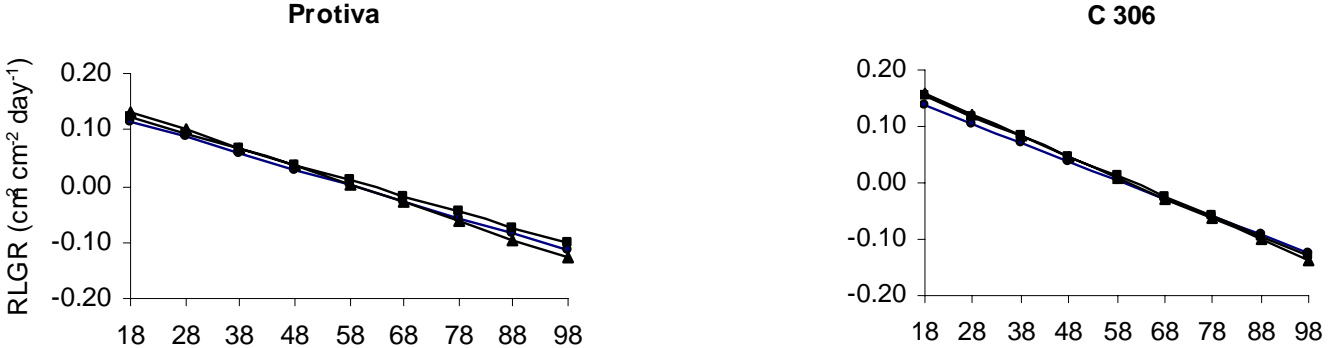

\section{Days after sowing}

Fig. 4b. Effects of different sowing dates on relative leaf growth rate (RLGR) of four wheat varieties at different stages of growth from quadratic fitted curve values (Second year). 

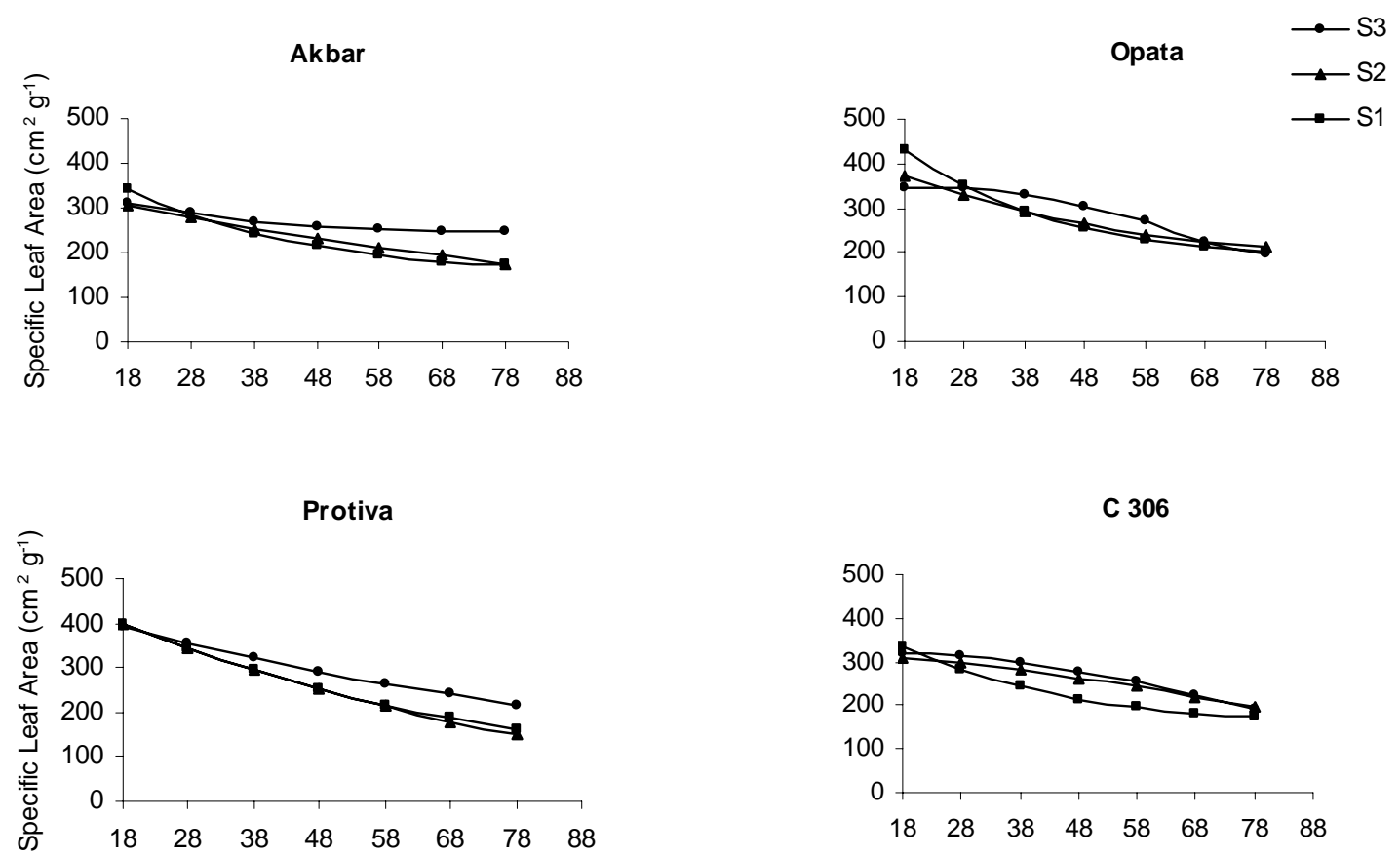

C 306

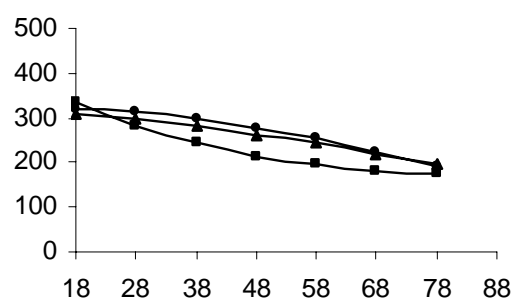

\section{Days after sowing}

Fig. 5a. Effects of different sowing dates on specific leaf area (SLA) of four wheat varieties at different stages of growth from quadratic fitted curve values (First year).
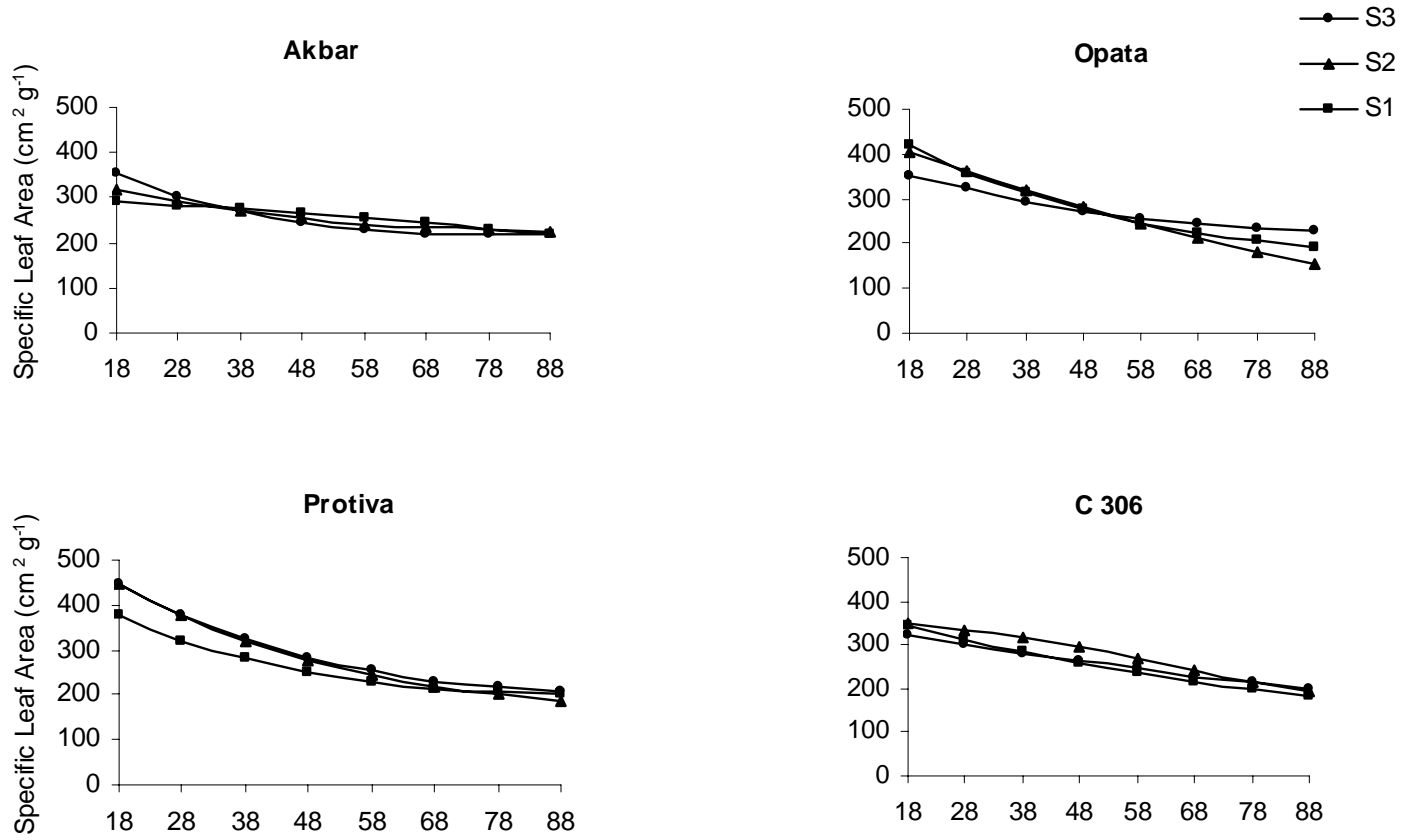

\section{Days after sowing}

Fig. 5b. Effects of different sowing dates on specific leaf area (SLA) of four wheat varieties at different stages of growth from quadratic fitted curve values (Second year). 

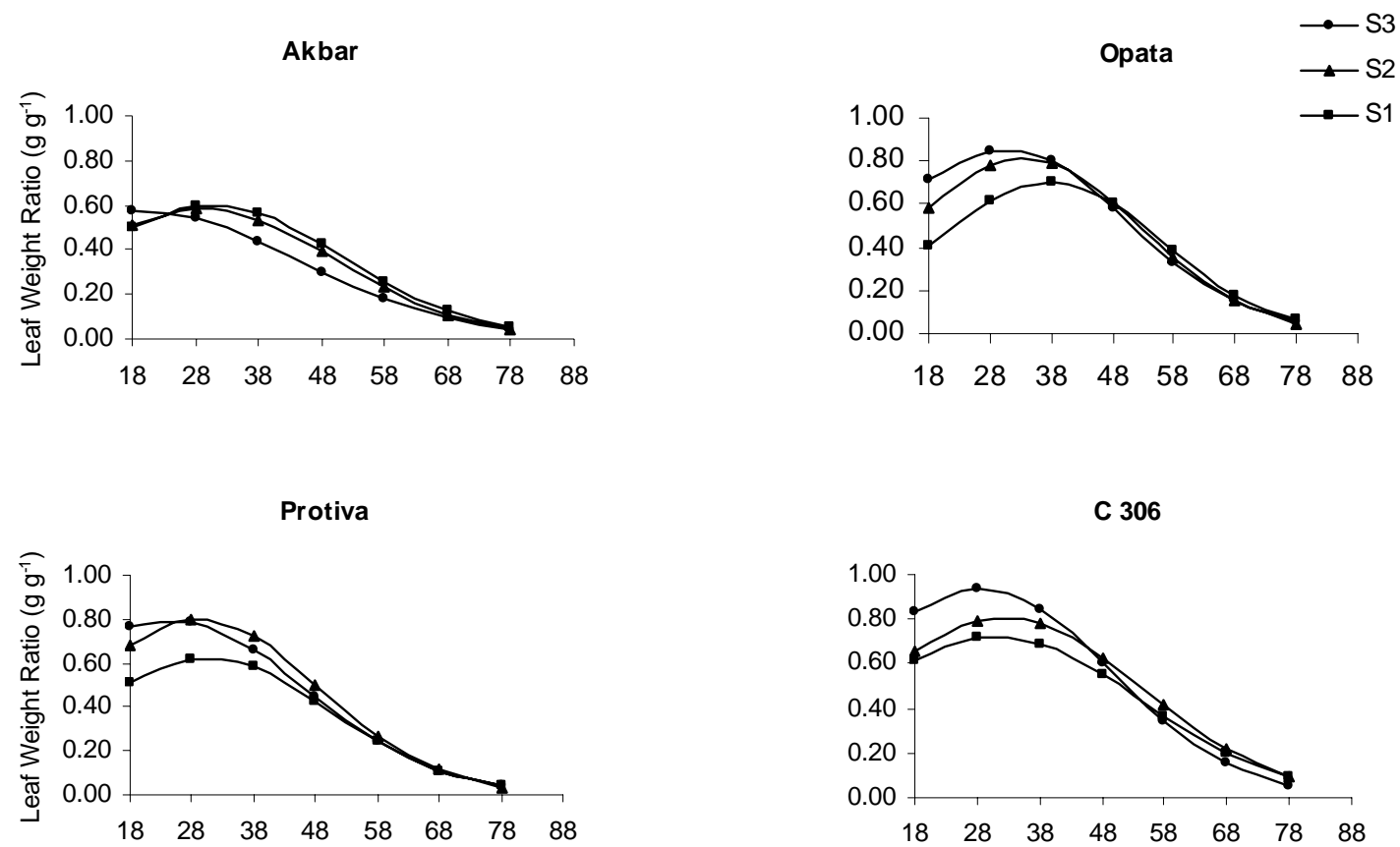

Days after sowing

Fig. 6a. Effects of different sowing dates on leaf weight ratio (LWR) of four wheat varieties at different stages of growth from quadratic fitted curve values (First year).
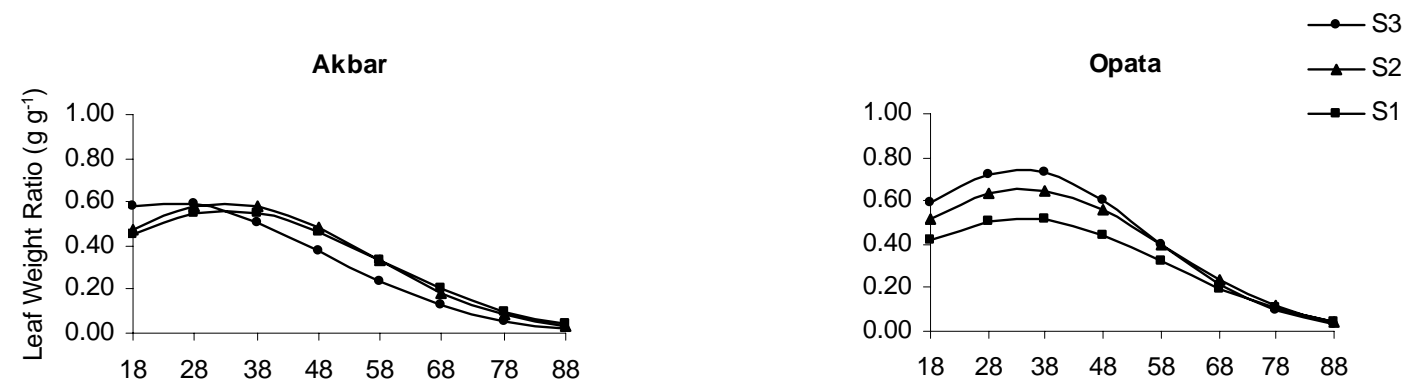

Protiva

C 306
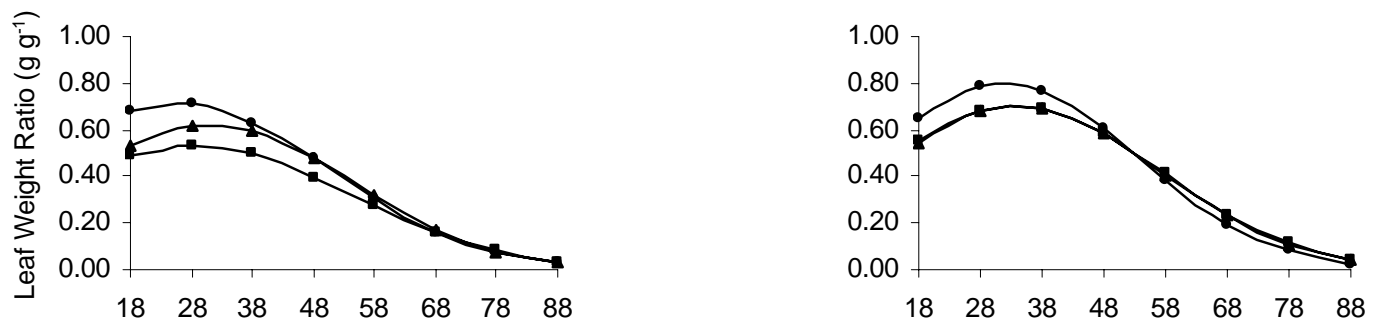

\section{Days after sowing}

Fig. 6b. Effects of different sowing dates on leaf weight ratio (LWR) of four wheat varieties at different stages of growth from quadratic fitted curve values (Second year). 


\section{References}

Allen EJ, Morgan DG. 1975. A quantitative comparison of the growth, development and yield of different varieties of oilseed rape. J agric Sci Camb 85, 387-393.

Buttery BR. 1969. Analysis of the growth of soybeans as affected by plant population and fertilizer. Can J Plant Sci 49, 675-684.

Chanda SV, Joshi AK, Vaishnav PP, Singh YD. 1987. Growth analysis using classical and curve-fitting methods in relation to productivity in pearl millet (Pennisetum americanum L.). J Agron Crop Sci 159, 312-319.

Clarke JM, Simpson GM. 1978. Growth analysis of Brassica napus cv. Tower. Can J Plant Sci 58, 587-595.

Haloi, B, Baldev B. 1986. Effect of irrigation on growth attributes in chickpea when grown under different dates of sowing and population pressure. Indian $\mathrm{J}$ Plant Physiol 29, 14-27.

Haque M. 1993. Studies on the physiological attributes and their relationship to yield in wheat under different soil moisture regimes. MSc Thesis. Bangladesh Agricultural University, Mymensingh, Bangladesh.

Hughes AP, Freeman PR. 1967. Growth analysis using frequent small harvests. J Appl Ecol 4, 553-560.

Hunt R. 1979. Plant growth analysis: the rationale behind the use of the fitted mathematical function. Ann Bot 43, 245-249.

Islam MM, Paul NK. 1986. Comparative growth analysis of six cultivars of rapeseed (Brassica campestris L.). Bangladesh J Agril Sci 13, 35-39.

Islam MT. 1992. Effect of soil moisture on dry matter distribution of wheat. Bangladesh J Train and Dev 5(2), 51-58.

Islam, M.S. and M.B. Soth. 1987. Growth and yield performance of winter and spring sown four cultivars of chickpea (Cicer arietenum L.). Bangladesh J Bot 16, 117-124.
Koller HR, Nyquist EW, Chorush IS. 1970. Growth analysis of the soybean community. Crop Sci 10, 407-412.

Nahar S, Paul NK. 1998. Growth analysis of wheat genotypes under different soil moisture regimes. Bangladesh J Agri 23, 57-64.

Nicholls AO, Calder DM. 1973. Comments on the use of regression analysis for the study of plant growth. New Phytol 72, 571-581.

Pandey RK, Saxena MC, Singh VB. 1978. Growth analysis of blackgram genotypes. Indian J agric Sci 48, 466-473.

Paul NK. 1980. Environmental effects on growth and development of Brassicae. Ph.D. Thesis. University of Wales, UK.

Rahman MS. 1993. Studies on drought adaptation of wheat (Triticum aestivum L.). M.Sc. Thesis. University of Rajshahi, Bangladesh.

Saha SK, Paul NK. 1995. Growth of five wheat (Triticum aestivum L.) cultivars as affected by soil moisture. J biosci 3, 103-112.

Sarker AM , Paul NK. 1998. Studies on growth attributes of wheat under irrigated and rainfed conditions. Bangladesh J Bot 27, 119-126.

Thorne GN. 1960. Variation with age in net assimilation rate and other growth attributes of sugar beet, potato and barley in a controlled environment. Ann Bot 24, 256-272.

Wallace DM, Munger HM. 1965. Studies on the physiological basis for yield differences. I. Growth analysis of six dry bean varieties. Crop Sci 5, 343-348.

Watson DJ. 1947. Comparative physiological studies on the growth of field crops. II. The effect of varying levels of nutrient supply on net assimilation rate and leaf area. Ann Bot 11, 375-407. 